\title{
DESEMPENHO PEDAGÓGICO: A EMERSÃO DA INTERDISCIPLINARIDADE NA EDUCAÇÃO BÁSICA À LUZ DA REESTRUTURAÇÃO CURRICULAR
}

\author{
Everton Bedin ${ }^{1}$ \\ José Claudio Del Pino
}

\begin{abstract}
Resumo: Considerando que avanços significativos vêm ocorrendo nos campos da formação continuada, do currículo, do saber discente e na qualificação dos processos de ensino e aprendizagem, tendo como eixos a vinculação teoria e prática e o trabalho interdisciplinar e contextualizado, o presente artigo teve por objetivo investigar e apresentar, na visão docente, como os trabalhos foram desenvolvidos à luz das construçóes curriculares efetivadas no sistema educacional gaúcho à emersão da interdisciplinaridade. A pesquisa qualitativa é de cunho descritivo-exploratório, para a qual se adotou a análise temática. A coleta de dados ocorreu via questionário estruturado. A análise dos dados, por meio da análise temática, ocorreu de forma quali-quantitativa. Após o término, pode-se perceber que os professores buscam a minimização do ensino fragmentado e sem nexo, evoluindo para um ensino pautado na interdisciplinaridade, na inter-relaçáo dos sujeitos e, dentre outros, na íntegra participação da comunidade escolar nos processos de ensino e aprendizagem.
\end{abstract}

Palavras-chave: Currículo. Ensino Médio. Politecnia. Interdisciplinaridade.

1 Graduado em Química, Licenciatura - UPF. Tem experiência na área de Química, com ênfase em Química. Pós-Graduado em Tecnologia de Informação e Comunicação na Educação - FURG. Mestre em Educação em Química - UFU. Doutor em Educação e Ensino em Ciências: química da vida e saúde - UFRGS. Pós-doutorando em Educação em Ciências pela UFRGS. Professor de Química na Educação Básica na rede pública e particular de ensino e na Universidade Luterana do Brasil - ULBRA -, campus Canoas.

2 Graduação em Química, Licenciatura e Industrial - PUCRS. Especialista em Química - UPF e UCS. Mestre em Ciências Biológicas-Bioquímica e Doutorado em Engenharia de Biomassa UFRGS. Pós-doutorado pela Universidade de Aveiro-Portugal (2004). Professor associado da UFRGS. Professor-Orientador do PPGQVS e do PPGQ - UFRGS. Bolsa de Produtividade em Pesquisa do Conselho Nacional de Desenvolvimento Científico e Tecnológico. 


\title{
PEDAGOGICAL PERFORMANCE: THE EMERGENCE FROM INTERDISCIPLINARITY IN BASIC EDUCATION IN THE LIGHT OF RESTRUCTURING CURRICULUM
}

\begin{abstract}
Whereas the significant advances have occurred in the fields of continuing formation, the curriculum, knowledge and student the qualification of teaching and learning processes having as axes linking theory and practice and the interdisciplinary and contextualized work, this article had to present results of an investigation that reports and presents the trajectory of teachers work, in the teaching view, how the works were developed in the light of curricular buildings effect in the educational system gaucho the emergence of interdisciplinarity. Qualitative research is descriptive and exploratory nature, for which it adopted the thematic analysis. The data were collected via structured questionnaire. The analysis of the data, through thematic analysis, it occurred in a qualitative and quantitative manner. After the finish, can be seen that teachers seek to minimize the fragmented teaching and senseless, evolving into an education based on interdisciplinarity, the interrelation of the subjects and, among others, the full participation of the school community in teaching and learning processes.
\end{abstract}

Keywords: Curriculum. High school. Polytechnic. Interdisciplinarity.

\section{INTRODUÇÃO}

A educação gaúcha brasileira, nos últimos anos, apresentava índices insatisfatórios de escolarização, formação e emancipação, especialmente no ensino médio. A escolaridade líquida (idade esperada para o ensino médio 15 - 17anos) era de apenas 53,1\%. A defasagem idade-série no Ensino Médio era de 30,5\%; da faixa etária de 15 a 17 anos, 108.995 jovens gaúchos ainda frequentavam o Ensino Fundamental. Ao mesmo tempo, constataram-se altos índices de abandono (13\%), especialmente no primeiro ano, e de reprovação $(21,7 \%)$ no decorrer do curso (SEDUCRS, 2011).

Este fato fez com que as políticas públicas do Estado do Rio Grande do Sul considerassem a necessidade de uma reestruturação sobre as políticas curriculares, acoplando-se a estas ações que não se configurassem em atividades prescritivas, homogeneizantes e centralizadas, tendo como base formativa o documento dos Parâmetros Curriculares para o Ensino Médio (PCNEM, 2002), o qual destaca a busca de novos recursos ao ensino. Essa proposta, que não é uma atividade fácil de ser concretizada, compreende que o ensino precisa mudar em virtude de uma nova sociedade cada vez mais tecnológica, a qual envolve questões sociais, culturais e formativas; envolve "[...] compreender que, apesar de o mundo ser o mesmo, os objetos de estudo são diferentes" (BRASIL, 1999, p. 20).

Assim, a partir deste mundo e da realidade educacional gaúcha, a reorganização curricular, proposta pelas políticas públicas, pretende superar a visão segmentada e meramente disciplinar por meio de perspectivas interdisciplinares e contextualizadas, embasadas nos eixos do PCNEM (2002), uma vez que estas devem "ser compreendidas a partir de uma abordagem relacional, propondo-se que, por meio da prática escolar, sejam estabelecidas interconexões e passagens 
entre os conhecimentos através de relações de complementaridade, convergência ou divergência" (BRASIL, 1999, p. 21).

Neste viés, a proposta de reestruturação do Ensino Médio, contida em um documento base, o qual foi construído considerando-se o Plano de Governo para o Estado do Rio Grande do Sul no período 2011-2014, os dispositivos da Lei de Diretrizes e Bases da Educação Nacional (LDB), - incluindo a concepção para o Ensino Médio no que diz respeito à sua finalidade e modalidades nela presentes -, além da Resolução sobre Diretrizes Curriculares para a Educação Básica emitida pelo Conselho Nacional de Educação (CNE), visou estabelecer "a democratização da gestão, do acesso à escola, ao conhecimento com qualidade cidadã; à aprendizagem e ao patrimônio cultural, e a permanência do aluno na escola, além da qualificação do Ensino Médio" (SEDUCRS, 2011, p. 1).

Neste desenho, a escrita do presente artigo destina-se a entender e refletir sobre a trajetória do trabalho docente após a reestruturação e a normatização do ensino médio em politecnia ${ }^{3}$, a qual se caracteriza por apresentar ações de "superação da dualidade entre cultura geral e cultura técnica" (SAVIANI, 1989, p. 8). Além de alimentar essa curiosidade epistemologia, neste artigo se propõe um conhecimento teórico relacionando as bases do currículo e as normas estabelecidas no regimento de reestruturação do ensino médio gaúcho, perpassando a leitura e análise por diversos trabalhos de pesquisa.

Desta forma, ressalva-se que o trabalho docente está conectado à atividade de cunho interdisciplinar na rede social facebook, considerando o tema norteador: Qualidade de Vida, para os diálogos e as reflexões sobre os diferentes assuntos tratados nas áreas de conhecimentos. Assim, tem-se que este trabalho se torna importante na medida em que se caracteriza na esfera politécnica, pois tem em sua concepção bases legais que se constituem no "aprofundamento da articulação das áreas de conhecimentos e suas tecnologias, com os eixos Cultura, Ciência, Tecnologia e Trabalho, na perspectiva de que a apropriação e a construção e conhecimento embasam e promovem a inserção social da cidadania" (SEDUC, 2011, p. 10).

\section{APORTES TEÓRICOS}

A construção de uma proposta para reestruturar o ensino médio gaúcho e passar a chamá-lo de Ensino Médio Politécnico (EMP) teve como fundamento uma concepção de conhecimento compreendido como "um processo humano,

3 [...] pensar políticas públicas voltadas para a educação escolar integrada ao trabalho, à ciência e à cultura, que desenvolva as bases científicas, técnicas e tecnológicas necessárias à produção da existência e a consciência dos direitos políticos, sociais e culturais e a capacidade de atingi-los (GRAMSCI, 1978). A noção de politecnia diz respeito ao domínio dos fundamentos científicos das diferentes técnicas que caracterizam o processo de trabalho produtivo moderno (SAVIANI, 1989). 
histórico, incessante, de busca de compreensão, de organização, de transformação do mundo vivido e sempre provisório" (SMED, 1999, p. 34).

Neste sentido, Gramsci (1999) afirma que o ser humano, enquanto conceito, deveria ser entendido como um ponto de chegada e não como um ponto de partida, isto é, "deve transformar-se continuamente com as transformações das relações sociais; também é possível dizer que a natureza do homem é a própria história" (GRAMSCI, 1999, p. 245). Com essa antinomia entre ponto de partida e ponto de chegada, o autor afirma que o homem é um constante fazer-se, sua identidade ou "unitariedade" se dá enquanto resultado de sua práxis; é produzida quando os homens estabelecem as condições materiais de sua existência, não está na partida, mas na chegada; o homem é o que ele faz na sua relação com o mundo e não o que fizeram dele.

Neste sentido, a existência do estudante não é dada pela sua natureza biológica, mas é produzida por ele mesmo, e é por isso que educação e trabalho são características histórico-ontológicas do ser humano. Assim, entende-se a necessidade da politecnia no berço das escolas gaúchas, pois o mundo moderno constitui-se por relações sociais e de produção de caráter excludente, as quais são resultados das formas capitalísticas de produção e reprodução da existência e do conhecimento. Desta forma, tornou-se necessário arquitetar um currículo que contemplasse ao mesmo tempo as dimensões relativas à formação humana e a científico-tecnológica, de modo a romper com a histórica dualidade que separa a formação geral da preparação para o trabalho.

O EMP, apesar de não profissionalizar os estudantes, busca desenvolver práticas de emancipação e formação, uma vez que se encontra "enraizado no mundo do trabalho e das relações sociais, de modo a promover formação científicotecnológica e sócio histórica a partir dos significados derivados da cultura, tendo em vista a compreensão e a transformação da realidade" (SEDUC, 2011, p. 15). Concomitante, pensa-se que a formação inicial do cidadão, a qual ocorre na educação básica, precisa compreender a educação como forma democrática e formativa em qualquer região para que possa, além de intervir na sua realidade de forma crítica e hábil, trabalhar em diferentes perspectivas, inclusive a de mudanças culturais e sociais.

No que tange à reestruturação do ensino médio gaúcho à luz da reorganização curricular (SEDUC, 2011), compreende-se que a politecnia conjetura novas formas de seleção e organização dos conteúdos a partir da prática sociocultural, considerando o diálogo entre as áreas de conhecimentos, supondo a primazia da relação entre o conhecimento protagonizado pelo educando sobre os saberes científicos do professor e, dentre outros, antepondo o significado do saber social sobre os critérios formais inerentes à lógica disciplinar.

Portanto, a construção desse currículo integrador instiga a quebra de paradigmas e o trabalho coletivo, agregando as diferentes disciplinas em áreas de conhecimentos e relacionando a ação do professor e dos estudantes como protagonistas dos processos da ensinagem; "O currículo é a forma de ter acesso 
ao conhecimento, não esgotando seu significado em algo estático, mas através das condições em que se realiza e se converte numa forma particular de entrar em contato com a cultura" (SACRISTÁN, 2000, p. 15).

Desse modo, percebe-se que as direções do PCNEM (2002) trabalham em sentidos múltiplos para orientar a reforma curricular, a concretização de uma base comum ao ensino, à conexão das disciplinas em áreas de conhecimentos, a exploração, socialização e contextualização do conhecimento por meio da interdisciplinaridade e, dentre outros, a relevância na necessidade de uma parte diversificada do currículo. Assim, entende-se que o currículo escolar situado em tempo-espaço cultural destina-se aos interesses sociais e políticos intrínsecos a cada época, nutrindo discussões e polêmicas em sua definição.

o significado do currículo é dado pelos próprios contextos em que se insere: a) um contexto de aula, no qual encontramos uma série de elementos como livros, professores, conteúdos, crianças; b) outro contexto pessoal e social, modelado pelas experiências que cada pessoa tem e traz para a vida escolar, refletidas em aptidões, interesses, habilidades, etc., além do clima social que se produz no contexto de classe; c) existe, além disso, outro contexto histórico escolar criado pelas formas passadas de realizar a experiência educativa, que deram lugar a tradições introjetadas em forma de crenças, reflexos institucionais e pessoais, etc., porque cada prática curricular cria, de alguma forma, incidências nas que a sucederão; d) finalmente, se pode falar de um contexto político, à medida que as relações dentro de classe refletem padrões de autoridade e poder, expressão de relações do mesmo tipo na sociedade exterior (SACRISTÁN, 1998, p. 22).

Ainda, as orientações educacionais energizaram a necessidade de o ensino médio desenvolver competências aos estudantes e professores, traçando um novo perfil para o currículo escolar, o qual deve estar:

[...] apoiado em competências básicas para a inserção de nossos jovens na vida adulta. Tínhamos um ensino descontextualizado, compartimentalizado e baseado no acúmulo de informações. Ao contrário disso, buscamos dar significado ao conhecimento escolar, mediante a contextualização; evitar a compartimentalização, mediante a interdisciplinaridade; e incentivar o raciocínio e a capacidade de aprender (BRASIL, 1999, p. 4).

Nesta perspectiva, percebe-se que a ideia de EMP traz orientações para um ensino contextualizado e interdisciplinar, pois reflete que a "interdisciplinaridade é um processo e, como tal, exige uma atitude que evidencie interesse por conhecer, compromisso com o aluno e ousadia para tentar o novo em técnicas e procedimentos" (SEDUC, 2011, p. 19).

Deste modo, entende-se que a reorganização curricular no ensino médio gaúcho, além de defender uma base curricular democrática e formativa, reforça a necessidade de melhores mudanças na esfera da educação, derivando-se na infraestrutura escolar e na formação docente. Em concordância, o PCNEM (2002) trabalha em uma "[...] reorganização curricular em áreas de conhecimentos, com 
o objetivo de facilitar o desenvolvimento dos conteúdos em numa perspectiva de interdisciplinaridade e contextualização" (BRASIL, 1999, p. 7).

$\mathrm{Na}$ busca por um saber mais integrado e autônomo, a interdisciplinaridade conduz a aprendizagem em uma metamorfose que pode alterar completamente $o$ curso dos fatos em educação; pode transformar o sombrio em brilhante, o tímido em audaz e o arrogante e a esperança em possibilidade (FAZENDA, 2008), uma vez que a mesma se caracteriza como um meio eficiente para a articulação e a relação entre o estudo da realidade e a produção de conhecimento com vistas à contextualização.

Assim, a interdisciplinaridade e a contextualização são apresentadas pelo PCNEM (2002) como possibilidades de ressignificação do conhecimento escolar a partir da reestruturação do currículo, pois contextualização significa "[...] assumir que todo conhecimento envolve uma relação entre sujeito e objeto" (BRASIL, 1999, p. 78).

A aprendizagem pressupõe a existência de um referencial que permita aos alunos identificar e se identificar com as questões propostas. Essa postura não implica permanecer apenas no nível de conhecimento que é dado pelo contexto mais imediato, nem muito menos pelo senso comum, mas visa a gerar a capacidade de compreender e intervir na realidade. Ao propor uma nova forma de organizar o currículo, trabalhado na perspectiva interdisciplinar e contextualizada, parte-se do pressuposto de que toda aprendizagem significativa implica uma relação sujeito-objeto e que, para que esta se concretize, é necessário oferecer as condições para que os dois pólos do processo interajam (BRASIL, 1999, p. 22).

Neste desenho, consideram-se a reestruturação curricular, a interdisciplinaridade, as áreas de conhecimentos, a parte diversificada do currículo e a contextualização como mecanismos facilitadores, significativos e mediadores para os processos de ensino e aprendizagem. Além do mais, pode-se observar que a proposta do EMP, estabelecida nas escolas gaúchas, está ao encontro das ações anexadas ao PCNEM (2002), pontuando as condições e necessidades básicas para a reorganização de um currículo para a Educação Básica.

Frente aos documentos oficiais, pesquisadores entendem que:

[...] são importantes do ponto de vista histórico e espera-se que potencializem a discussão de uma alternativa para o ensino das ciências no Brasil. Seja pelo caminho neles propostos, seja por outro. Entretanto, apenas a elaboração e distribuição desses documentos aos professores não terão efeito algum. Espera-se que isso se dê acompanhado de políticas educacionais efetivas, que visem a garantir uma escola de qualidade a todos os alunos, essa deveria ser a grande meta a ser alcançada, mesmo ciente de que tal desafio irá encontrar obstáculos de igual magnitude (RICARDO, 2005, p. 246). 
Destarte, destaca-se que em 2002 foram lançadas as Orientações Educacionais Complementares aos Parâmetros Curriculares Nacionais $-\mathrm{PCN}+{ }^{4}$ (BRASIL, 2002), onde, novamente, se destacam as áreas de conhecimentos, aflorando claramente alguns conteúdos como base de referência curricular. Portanto, entende-se que as orientações escolares, presentes nos documentos normativos da educação brasileira, quando interpretadas de forma hábil e crítica, asseguram, a partir do desenvolvimento de competências e habilidades, pelos segmentos escolares a representação de um novo paradigma na educação, o qual pode qualificar os processos de ensino, de aprendizagem e de avaliação.

\section{DESENHO DA PESQUISA}

Este estudo é de natureza qualitativa de cunho descritivo-exploratório, para o qual se adotou a análise temática (MINAYO, 1999). Para esta análise, segundo a autora, o pesquisador precisa desdobrar os dados em quatro etapas: "pré-análise, exploração do material, tratamento dos resultados e interpretação" (MINAYO, 1999, p. 209). Assim, entende-se que é necessário estar sempre buscando alcançar os objetivos traçados, uma vez que se podem reformular os dados por meio da interpretação.

[...] a análise temática visa verificar hipóteses e ou descobrir o que está por trás de cada conteúdo manifesto. [...] o que está escrito, falado, mapeado, figurativamente desenhado e/ou simbolicamente explicitado sempre será o ponto de partida para a identificação do conteúdo manifesto (seja ele explícito e/ou latente). A análise e a interpretação dos conteúdos obtidos enquadramse na condição dos passos (ou processos) a serem seguidos (MINAYO, 2003, p. 74).

Os sujeitos deste estudo foram os professores que atuam nas quatro áreas de conhecimentos nos dois segundos anos do Ensino Médio Politécnico (turmas 201, 202), em uma escola pública ao norte do Estado do Rio Grande do Sul. Os dados foram coletados por meio de um questionário estruturado em três questões, sendo duas delas de múltipla escolha e uma descritiva. As questões visaram entender e compreender o trabalho e a visão dos professores sobre a reestruturação curricular no estado gaúcho, além de averiguar como o trabalho docente vem influenciando na qualificação dos processos de ensino e aprendizagem, no relacionamento com o estudante e com as áreas de conhecimentos.

Os professores foram convidados a responder o questionário durante uma semana. Foram convidados 8 professores que trabalhavam em sala de aula com as turmas 201 e 202. A análise dos dados foi referenciada na análise temática, que consiste em apreender os núcleos de sentido que compõem uma comunicação, cuja

$4 \mathrm{O}$ PCN+ é um complemento ao PCNEM (2002), aprofundando situações que podem desencadear competências e habilidades em cada disciplina. Destaca exemplos de situações que exploram conhecimentos científicos reforçando as condições estratégicas para um novo ensino. 
presença ou frequência signifiquem alguma coisa para o objetivo analítico visado (MINAYO, 1999).

Em outras palavras, buscou-se realizar uma média entre as respostas dos professores das diferentes disciplinas e, a partir desta, analisar os questionários por áreas de conhecimentos, por exemplo, analisaram-se os questionários dos professores de Física, Química e Biologia para, posteriormente, plotar o gráfico da área das Ciências da Natureza, o qual representa a média das respostas destes professores. Ainda, junto a análise temática, buscou-se realizar uma interpretação dos dados de forma quali-quantitativa, a fim de obter uma visão significativa dos resultados, pois "uma possibilita estimativa numérica (quantitativa) e a outra proporciona visibilidade e aprofundamento nos significados das questões (qualitativa)" (MATOS; VIEIRA, 2001, p. 35).

Assim, considerar a qualificação sobre as questões que findam o currículo escolar no ensino gaúcho é possibilitar a valorização, as percepções e as descrições de um grupo de professores que, de certa forma, apresentam suas situações contextuais em suas interações. Além disso, o questionário ajuda a perceber "o particular como instância da totalidade social, procurando compreender os sujeitos envolvidos e, por sua vez, compreender também o contexto" (FREITAS, 2002, p. 26).

Todavia, ressalva-se com as palavras de Minayo (2001, p. 79) que "o produto final da análise de uma pesquisa, por mais brilhante que seja, deve ser sempre encarada de forma provisória e aproximativa". Tal posicionamento aponta como base que, "em se tratando de ciência, as afirmações podem superar conclusões prévias a elas e podem ser superadas por outras afirmações futuras". Na realidade, esse é o percurso da ciência, principalmente daquelas em que a população de amostra são pessoas, pois estas possuem suas identidades mutáveis, estão em constante transgressão, mudando e evoluindo a todo instante; logo, quaisquer interpretações sobre os dados desta pesquisa podem, de alguma forma, derivar em resultados, puramente, divergentes.

\section{RESULTADOS E DISCUSSÓES}

Para melhor compreensão dos resultados obtidos, apresentaram-se as respostas às questões separadamente; a análise das três questões que compuseram o questionário ocorreu individualmente, dando-se ênfase à forma quali-quantitativa. A parte qualitativa ocorreu via análise temática, abordando-se teóricos que se aproximam da complexidade e singularidade das respostas dos professores. A análise quantitativa foi apresentada por meio da média aritmética estabelecida na área via utilização de quadros e matrizes.

A primeira questão disponibilizada, e que instigou os professores a apontarem suas concepções, visou entender as percepções docentes pós-reestruturação no ensino médio gaúcho. Para tanto, a questão apresentada continha subquestões, as quais deveriam ser destacadas pelos professores em uma galga de satisfação. Este índice de satisfação foi representado por uma escala de números variando de 1 à 
10 pontos, sendo o número 1 o menor ponto e o número 10 o maior ponto, como representado na figura 1 abaixo.

Figura 1 - Representação da questão disponibilizada sobre o currículo

\begin{tabular}{|l|l|l|l|l|l|l||}
\hline \multicolumn{2}{|c|}{} & 1 à 2 & 3 à 4 & 5 à 6 & 7 à 8 & 9 à 10 \\
\hline \multirow{2}{*}{$\begin{array}{l}\text { Em relação } \\
\text { ao Currículo, } \\
\begin{array}{l}\text { tem-se que } \\
\text { ele foi: }\end{array}\end{array}$} & Flexível & & & & & \\
\cline { 2 - 8 } & Relacionado com a pesquisa sócio-antropológica & & & & & \\
\hline & Relacionado com o conteúdo & & & & & \\
\hline
\end{tabular}

Fonte: Os autores (2016).

Frente a esta questão, plotou-se a tabela abaixo que apresenta os apontamentos dos 8 professores (áreas de conhecimento) às subquestões. Destaca-se que as subquestões foram, para facilitar o processo de compreensão e sistematização, simplificadas em A (Flexive), B (Relacionado com a pesquisa sócio-antropológica), C (Relacionado com o conteúdo) e D (Facilitado ao material de apoio). Igualmente, para assegurar a identidade de cada sujeito, os professores foram considerados sigilosamente por P1 até P85.

Tabela 1 - Média entre as disciplinas frente a questão de número 1

\begin{tabular}{|c|c|c|c|c|c|c|c|c|c|c|c|c|c|c|c|c|}
\hline & \multicolumn{3}{|c|}{ P1, P7, P8 } & \multicolumn{4}{c|}{ P2 } & \multicolumn{3}{c|}{ P3, P5 } & \multicolumn{3}{c|}{ P4, P6 } \\
\cline { 2 - 15 } & A & B & C & D & A & B & C & D & A & B & C & D & A & B & C & D \\
\hline 1 à 2 & & & & & & & & & & & & & & & & \\
\hline 3 à 4 & & & & & & & & & & & & & & & & \\
\hline 5 à 6 & & & & & & & & & & & & & & & & \\
\hline 7 à 8 & & $\mathrm{X}$ & $\mathrm{X}$ & & $\mathrm{X}$ & $\mathrm{X}$ & $\mathrm{X}$ & & & & $\mathrm{X}$ & & & & & \\
\hline 9 à 10 & $\mathrm{X}$ & & & $\mathrm{X}$ & & & & $\mathrm{X}$ & $\mathrm{X}$ & $\mathrm{X}$ & & $\mathrm{X}$ & $\mathrm{X}$ & $\mathrm{X}$ & $\mathrm{X}$ & $\mathrm{X}$ \\
\hline
\end{tabular}

Fonte: Os autores (2016).

Considerando a tabela acima, pode-se perceber que os professores encontram dificuldades na reestruturação curricular em relação à subquestão: relacionado com 0 conteúdo, uma vez que o currículo passou a exigir dos professores competências e habilidades em trabalhar com o novo a partir da vivência do educando para a emersão da interdisciplinaridade. Do mesmo modo, percebe-se a dificuldade em lograr uma escala de 10 pontos para a subquestão: Relacionado com a pesquisa sócio-

5 P1: Português e Inglês. P2: Matemática. P3: História e Geografia. P4: Química e Física. P5: Sociologia e Filosofia. P6: Biologia. P7: Educação Física. P8: Arte e Espanhol. 
antropológica, uma vez que esta emerge do contexto do educando e precisa da acessibilidade do professor para se vincular ao científico.

Neste desenho, percebe-se que há a necessidade de os professores, enquanto responsáveis por um papel de formação, membros de uma escola e de um estado, desenvolverem atividades de concepção e/ou de aperfeiçoamento frente às práticas de ensino interdisciplinar, uma vez que a questão curricular perpassa ações culturais, históricas e sociais. Assim, "a cultura popular é um conhecimento que deve, legitimamente, fazer parte do Currículo, pois toda cultura é fruto do trabalho humano" (ALBUQUERQUE; KUENSLE, 2006, p. 102).

Desta maneira, tem-se que "o currículo é uma determinação da ação e da prática, assim como são as valorizações sobre o que é cultura apropriada" (SACRISTÁN, 1998, p. 48). Nesta relação entre cultura e sistema educacional institucionalizado, Sacristán (1999, p. 180) assinala que a "escolaridade será vista como uma cultura" e que a "a educação é reprodução e também aposta na construção de um projeto para os sujeitos, para a sociedade e, portanto, ela mesma é criadora de cultura no sentido de transformar a cultura existente, assim, educar requer um projeto com uma direção [...]". Sobrepõe, ainda, que "a educação serve não só para reproduzir realidades, mas para reconstruir a tradição que compõem a cultura, ou as culturas, e alcançar um ideal de vida, que é o desafio do futuro" (SACRISTÁN, 1999, p. 181).

Em contrapartida, os professores admitem que o currículo pós reformulação passou a ser mais Flexivel e Facilitado ao material de apoio; logo, trabalhar com um currículo flexível, o qual parte das noções e/ou adaptações dos conteúdos por parte dos professores, faz com que os processos de ensino e aprendizagem sejam exercidos com qualidade e equidade, além de estarem vinculados aos materiais didáticos disponíveis.

Neste desenho, é perceptível que as práticas pedagógicas abarcaram um novo rumo, possibilitando um conhecimento científico contextualizado a realidade do educando, proporcionando-lhe saberes para a vida, não para o vestibular. Da mesma forma, faz com que haja maior interação entre os sujeitos envolvidos no processo, pois faz com que a sala de aula seja um lugar de diálogo, construção e troca de informações. Corroborando, Sacristán e Pérez Gómez (2000, p. 123) esboçam que "o ensino é o conjunto de atividades que transforma o currículo na prática para produzir a aprendizagem, é uma característica marcante do pensamento curricular atual".

A segunda questão, também de múltipla escolha, disponibilizada no questionário aos professores, enfatizava a questão do Ensino Médio Politécnico, mais precisamente referindo-se ao funcionamento desta modalidade de ensino na escola onde trabalham os professores. Para tanto, ofereceu-se 10 opções, consideradas motivos e/ou afirmações, para o funcionamento da politecnia na escola. Destas 10 opções, apenas uma delas compreendia a questão outros, onde o professor que a apontasse poderia justificar.

As opções disponibilizadas frente a questão foram: 
A. Tem apoio dos professores;

B. Tem apoio da comunidade escolar;

C. Tem apoio da coordenação;

D. $\quad$ A direção se empenha em ajudar;

E. Professores exigentes;
F. A escola possui infraestrutura;

G. Alunos se dedicam;

H. Coordenação cobra;

I. Única escola estadual do município;

J. Outros.

A apresentação da análise para esta questão foi feita por meio de gráficos que concebem em média os apontamentos dos professores das áreas de conhecimentos. Ressalva-se que os gráficos se apresentam em sequência, sendo: Ciências da Natureza, Humanas, Linguagens e Matemática.

Gráfico 1 - Média das concepções dos professores da área de Ciências da Natureza

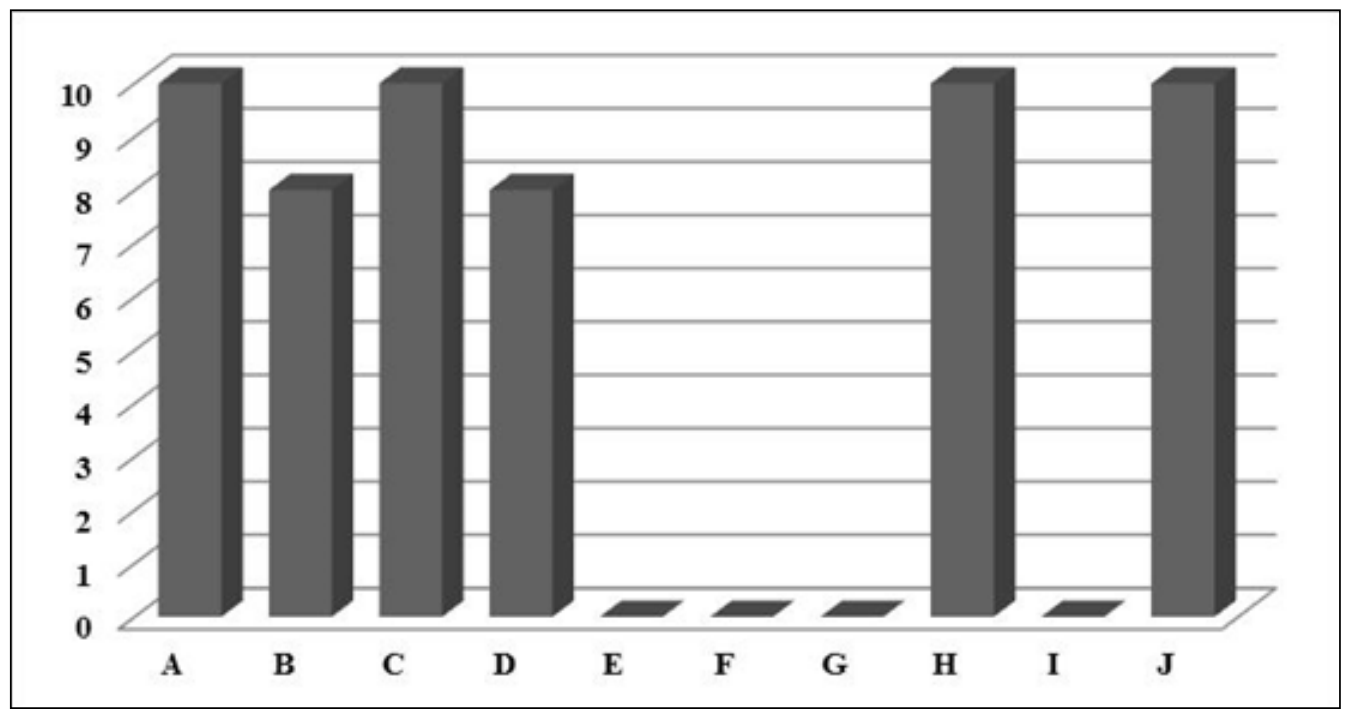

Fonte: Os autores (2016).

Analisando-se o gráfico que apresenta a média dos professores da área de Ciências da Natureza, pode-se perceber que dentre os motivos que fazem com que o Ensino Médio Politécnico desenvolva-se na escola estão o apoio docente, o apoio e a cobrança da coordenação e, como destacado na opção outros, pelo professor 4: "trabalhos e conteúdos normais, não existe muita diferença, apenas a necessidade de conectar esses conteúdos a realidade do educando por meio das outras áreas, favorecendo as pesquisas".

A pesquisa é mencionada pelo professor por ocasionar uma diferença no planejamento dos professores, favorecendo a inter-relação entre os agentes deste processo e a qualidade aos processos de ensino e aprendizagem, pois a pesquisa na prática pedagógica é a garantia da construção de novos conhecimentos; "'a partir da articulação da análise de seus resultados com o acúmulo científico das áreas 
de conhecimento, dar-se conta da necessidade ou realidade a ser transformada" (SEDUCRS, 2011, p. 21).

Desta forma, entende-se que os professores e a coordenação da escola são pontos-chave para o bom funcionamento e desenvolvimento da politecnia via pesquisas, uma vez que, como membros de formação ética e reflexiva, os professores precisam estar acompanhando todas as atividades de pesquisa que se desenvolvem na escola, proporcionando entusiasmo, ânimo e coragem aos discentes, além de apresentarem, por meio da interação dialógica e construtivista, competências e habilidades.

Assim, tem-se que a pesquisa escolar, motivada e orientada pelos professores, implica na identificação de uma dúvida ou de um problema, na seleção de informações de fontes confiáveis, na interpretação e elaboração dessas informações e na organização e relato sobre o conhecimento adquirido. Portanto, a pesquisa propicia o desenvolvimento da atitude científica, o que significa contribuir, dentre outros aspectos, para o desenvolvimento de condições de interpretar, analisar, criticar, refletir, rejeitar ideias fechadas, aprender, buscar soluções e propor alternativas, potencializadas pela investigação e pela responsabilidade ética assumida diante das questões políticas, sociais, culturais e econômicas (BRASIL, 2011).

Nesta perspectiva, entendem-se as palavras de John Kerr, citado por Forquin (1993, p. 23), quando define o currículo como "toda aprendizagem organizada ou conduzida pela escola, que se efetua no contexto de um grupo de maneira individual, no interior ou no exterior da escola". Assim, o currículo pode ser entendido como "um programa de atividades dos professores e dos alunos, concebido de maneira que os alunos alcancem na medida do possível certos fins ou certos objetivos educativos" (FORQUIN, 1993, p. 23).

Quanto às concepções dos professores da área das Humanas, pode-se perceber que os mesmos estão ao encontro das concepções dos professores das Ciências da Natureza, mas elencam a opção $\mathrm{G}$ (Alunos se dedicam) para revelar que as atividades são desenvolvidas em conjunto. Observe o gráfico 2 abaixo. 
Gráfico 2 - Média das concepções dos professores da área das Humanas

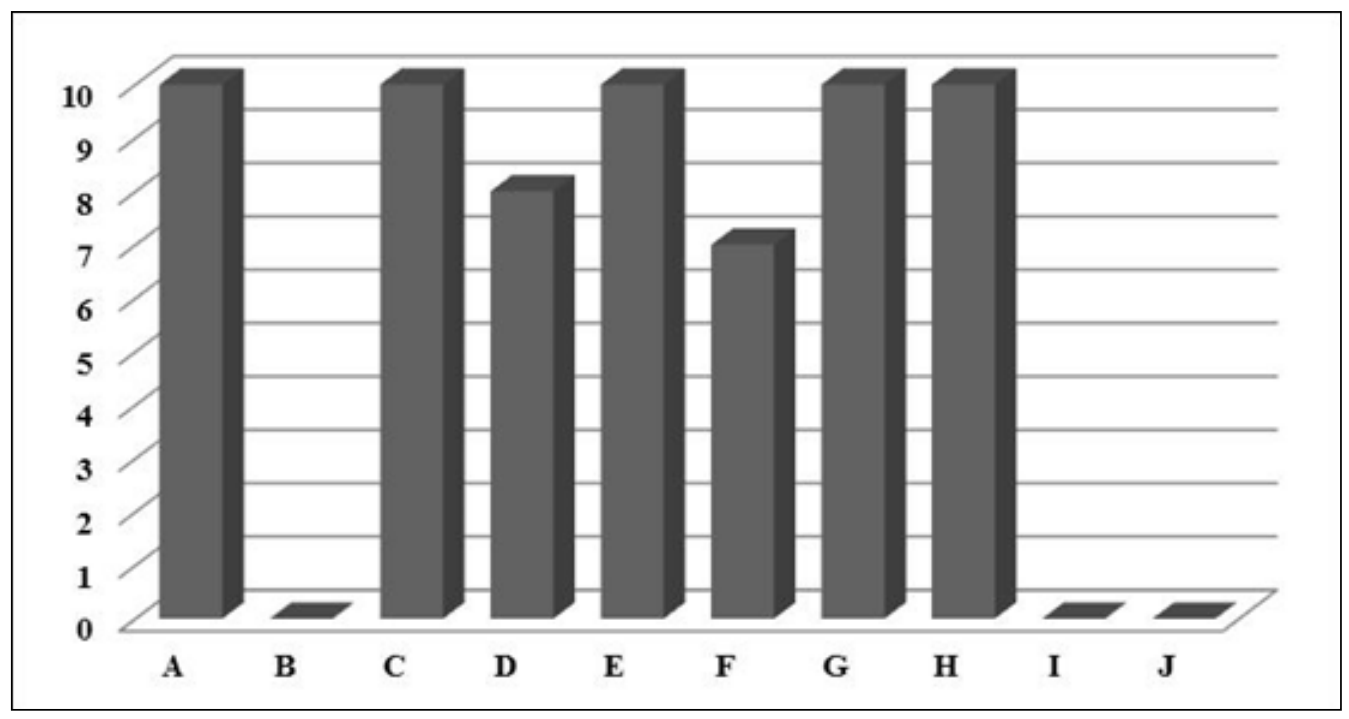

Fonte: Os autores (2016).

Nesta teia, percebe-se que os estudantes, cada vez mais, estão buscando autonomia e criticidade nas atividades realizadas dentro da escola; deixam de ser agentes passivos para, em conjunto com os colegas e professores, serem atores da própria formação. Nesse viés, Pinheiro (2010) afirma que o professor deve vivenciar e entender a realidade do estudante, buscando enxergar as coisas sobre as perspectivas dele, no avesso adotará uma conduta não favorável em sala de aula. "Se houver essa divisão entre professores e alunos a conivência entre eles diminuirá e, consequentemente, a eficácia do ensino" (PINHEIRO, 2010, p. 407).

Em decorrência, o currículo é concebido como o conjunto das relações desafiadoras das capacidades de todos, que se propõe a resgatar o sentido da escola como espaço de desenvolvimento e aprendizagem, dando sentido para o mundo real, concreto, percebido pelos alunos e alunas. Conteúdos são organizados a partir da realidade vivida pelos alunos e alunas e da necessidade de compreensão desta realidade, do entendimento do mundo (SEDUCRS, 2011, p. 15).

Observando-se o gráfico 3 abaixo, representando as concepções em média dos professores da área de Linguagens, averígua-se que existem algumas oscilações entre as opções, mas é compreensível que os professores, assim como as outras áreas suprademonstradas, percebem que a politecnia está em funcionamento na escola por apresentar apoio dos professores e da coordenação.

Dentre outros, os professores destacam uma opção que até então não havia sido apontada: B (Apoio da comunidade), revelando que a comunidade, nesta reestruturação de ensino, passou a estar mais presente na escola e, por meio de auxílio e apoio às pesquisas, impactar de forma positiva. Assim, percebe-se o quão 
importante é a presença da comunidade escolar para um bom desenvolvimento dos processos educacionais, pois "a construção do currículo do Ensino Médio Politécnico exige a participação de todos, uma vez que tem o pressuposto do trabalho participativo e coletivo na escola" (SEDUCRS, 2011, p. 27).

Gráfico 3 - Média das concepções dos professores da área das Linguagens

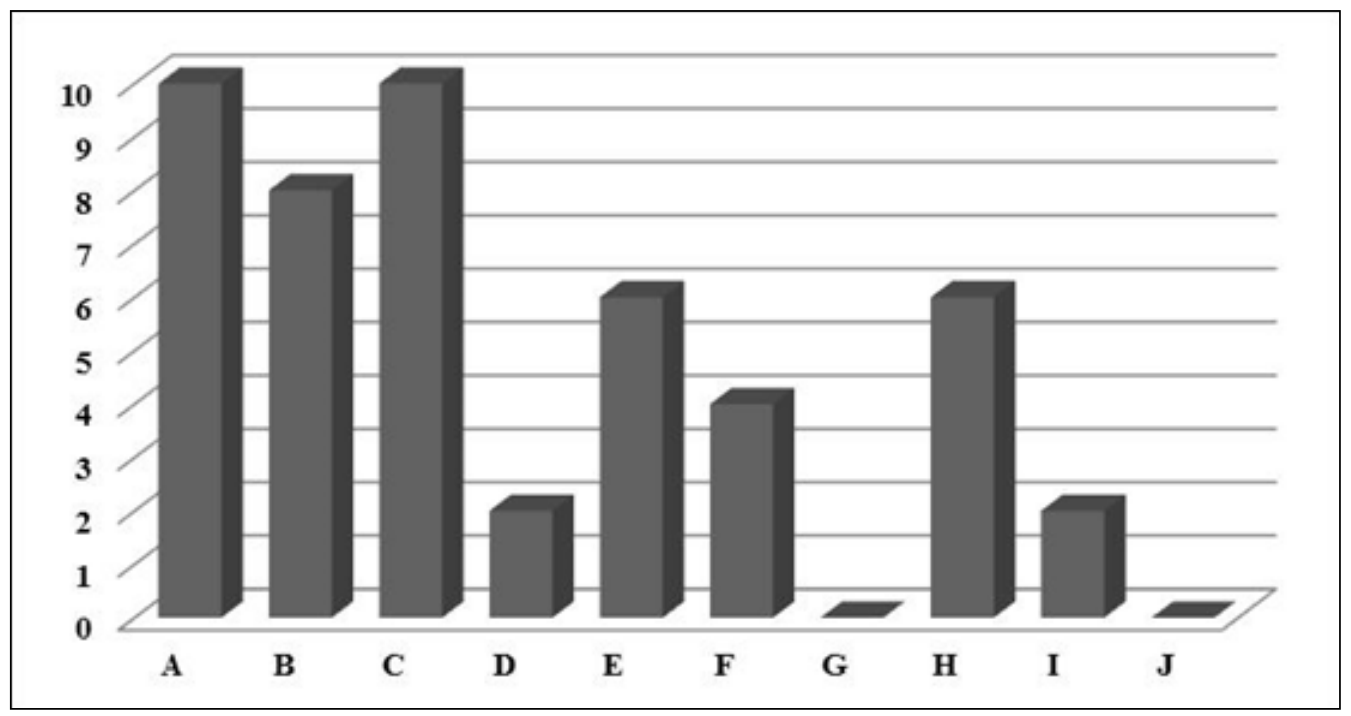

Fonte: Os autores (2016).

Além do mais, a comunidade escolar precisa estar pautada nas normas da politecnia, uma vez que auxilia os estudantes na prática e no desenvolvimento dos projetos de pesquisa ${ }^{6}$, valorizando a formação cidadã no eixo da cultura, ciência, tecnologia e trabalho. Assim, ressalva-se que "a prática democrática se instala neste processo de reestruturação a partir do debate deste documento-base nas escolas e com a participação de toda a comunidade escolar" (SEDUCRS, 2011, p. 4).

[...] o professor não apenas transmite uma informação e faz perguntas, mas também ouve os alunos. Deve dar-lhes atenção e cuidar para que aprendam a expressar-se, a expor opiniões e dar respostas. O trabalho docente nunca é unidirecional (LIBÂNEO, 1994, p. 250).

Neste sentido, demonstra-se o gráfico abaixo que representa a concepção do professor da área de Matemática. Nele, pode-se perceber que as opções A e $\mathrm{H}$ são as mais indicadas no decorrer do trabalho desenvolvido na escola, isto é,

6 Projetos de pesquisa são atividades desenvolvidas na disciplina de Seminário Integrado, os quais visam a articulação dos dois blocos do currículo, dando-se pela interlocução, nos dois sentidos, entre as áreas de conhecimento e os eixos transversais, oportunizando apropriação e possibilidades do mundo do trabalho. $\mathrm{O}$ desenvolvimento destes projetos que se traduzem por práticas, visitas, estágios e vivências pode ocorrer também fora do espaço escolar e fora do turno que o aluno frequenta (SEDUCRS, 2011). 
sem o apoio dos professores e a cobrança da coordenação, talvez, os trabalhos não fossem realizados de forma hábil e adjunta às atividades extracurriculares.

Gráfico 4 - Média das concepções dos professores da área da Matemática

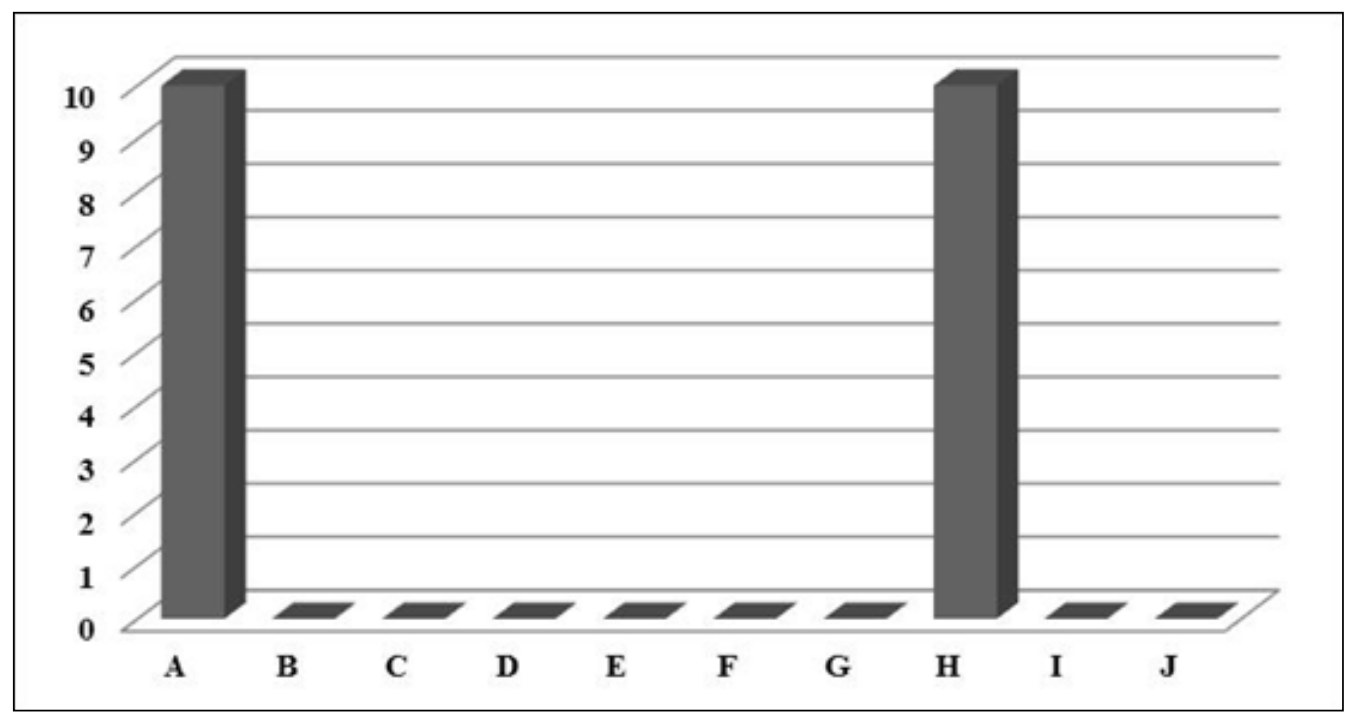

Fonte: Os autores (2016).

Nesta perspectiva, entende-se que o trabalho sobre a politecnia, pósreestruturação curricular, só ocorre na escola devido o apoio dos professores, da direção, da comunidade escolar e da cobrança significativa da coordenação, sempre exigindo dos professores e instigando os alunos a desenvolverem os trabalhos com qualidade e relevância. Portanto, escola vem desenvolvendo atividades de pesquisa e extensão em um viés colaborativo e formativo, pois auxilia os sujeitos a trabalharem no coletivo, buscando subsídios na comunidade escolar e na vivência com o outro.

Propõe-se, assim, uma escola de ensino médio que atue como uma
comunidade de aprendizagem. Nela, os jovens desenvolverão uma cultura para
o trabalho e demais práticas sociais por meio do protagonismo em atividades
transformadoras. Explorarão interesses vocacionais ou opções profissionais,
perspectivas de vida e de organização social, exercendo sua autonomia e
aprendendo a ser autônomo, ao formular e ensaiar a concretização de projetos
de vida e de sociedade (UNESCO, 2011, p. 9).

No fim do questionário, a fim de compreender teoricamente e, a partir de uma análise minuciosa sobre as escrituras dos professores, refletir sobre as concepções e perspectivas que estes carregam sobre a questão de currículo, disponibilizou-se uma questão aberta. A questão que instigou os professores a responder, considerando suas ideias e percepções, foi: em relação ao curriculo, apresente os benefícios e os malefícios em trabalhar de forma diferenciada, isto é, na relação com a outra área.

Para a análise desta questão, optou-se em apresentar um SmartArt em forma de palavras-chave; este revela os apontamentos docentes em decorrência dos 
benefícios e dos malefícios, além de alguns trechos que assinalam a real atuação dos professores na proliferação de informações para a concepção e qualificação dos processos de ensino e aprendizagem.

Figura 2 - Relação das palavras-chaves da questão dissertativa

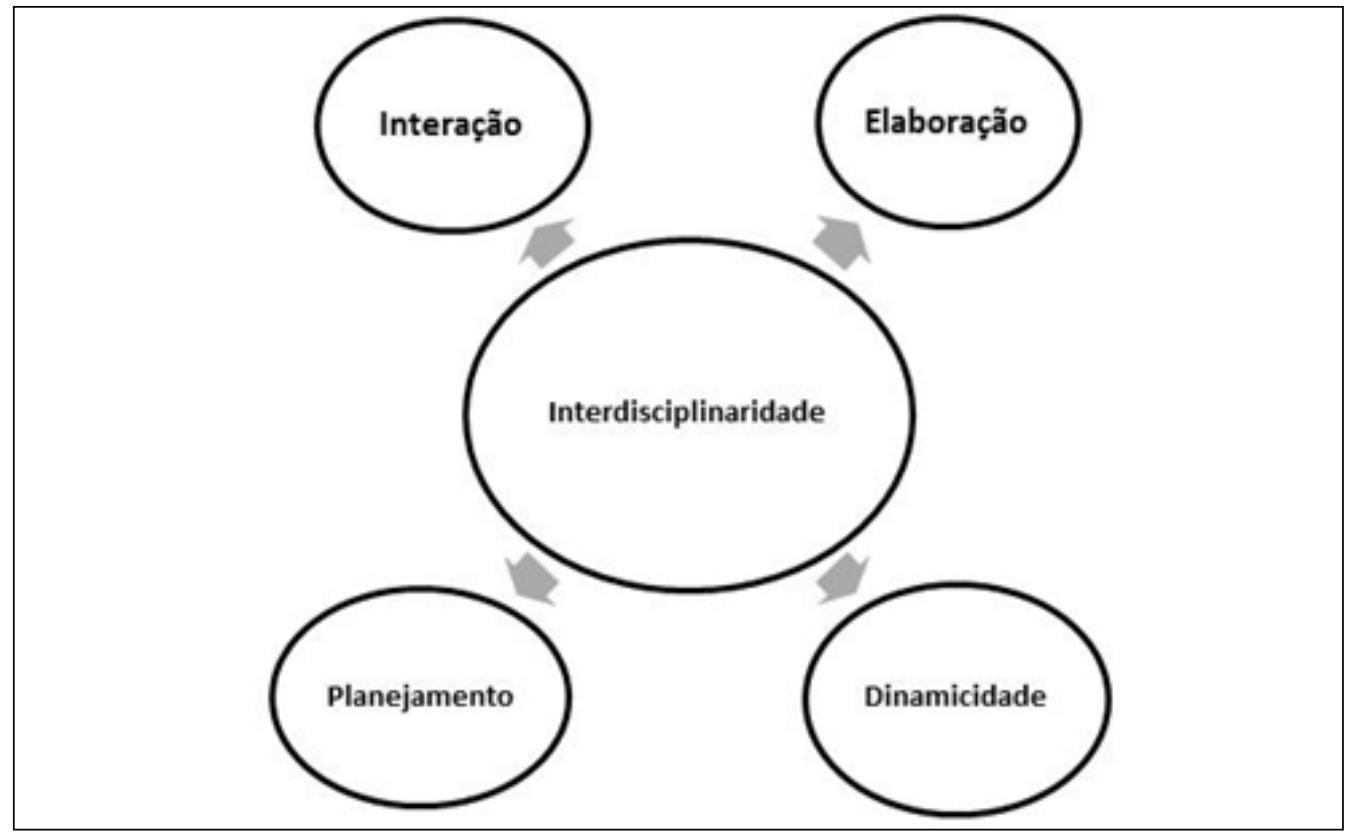

Fonte: Os autores (2016).

Observando o SmartArt (figura 2) acima, percebe-se que os professores analisam a emersão da interdisciplinaridade por meio de alguns mecanismos, tais como: planejamento, dinamicidade, interação e elaboração. Nesta vertente, entende-se que para a interdisciplinaridade surgir no trabalho docente deve haver, essencialmente, um dos requisitos apontados pelos professores, pois há uma ligação, ligeiramente significativa, entre os trabalhos serem planejados em conjunto, em meio a dinâmica e a interação, para serem desenvolvidos no viés da interdisciplinaridade.

Por ventura, se entende, a partir de uma análise sobre as escrituras dos professores, que tais mecanismos são, ao mesmo tempo, benefícios e malefícios advindos com a reestruturação curricular, pois os professores alegam que um ensino qualificado, de forma colaborativa e dialógica, precisa ser planejado e elaborado em conjunto com o educando, favorecendo a dinâmica e a interação interdisciplinar entre todos os sujeitos envolvidos.

Ao mesmo tempo, a partir de uma análise textual sobre escrituras/respostas, pode-se entender que os professores ajuízam a ideia de que planejar e elaborar atividades de forma dinâmica na interação com o outro é complicado, pois estão acostumados a vivenciar e praticar um planejamento individual e dissociado das 
outras áreas; uma elaboração fragmentada e defasada dos processos de ensino e aprendizagem de forma não interdisciplinar.

Assim, sendo de essencial importância para o sucesso de qualquer reformulação curricular, percebe-se a indispensabilidade de uma formação docente continuada que possa garantir trabalhos de forma contextualizada e interdisciplinar. O êxito desta reestruturação curricular, por deveras, pode estar diretamente vinculado à formação dos professores, as condições adequadas de trabalho, a um salário digno, além de outros subsídios, como materiais didáticos e recursos humanos.

Contudo, os professores pesquisados ressalvam que "a proposta da politecnia é trabalhar de forma interdisciplinar, todas as áreas trabalhando em conjunto, apenas somando; uns ajudam os outros, o que contribui para o conhecimento dos professores bem como dos alunos" (P1). "Quando se trabalha em conjunto, um professor pode contribuir no trabalho do outro, ajudando o aluno a compreender melhor um determinado conteúdo" (P3). Entretanto, admite-se nas palavras de P4 que:

[...] a dificuldade está em entender e se relacionar com o outro, mas, mesmo diante disto, existe o benefício: o trabalho em conjunto; a aprendizagem de forma conexa, um saber relacionado entre as áreas; facilidade em adquirir informações de forma científica e se constituir enquanto sujeito crítico e social do relacionamento entre o saber do contexto com o científico.

Em concordância, Lopes (2006), Silva (2005) e Sacristán e Pérez Gómez (2000) afirmam que o currículo não é uma listagem de conteúdos, mas um processo constituído por um encontro cultural, saberes, conhecimentos escolares na prática da sala de aula, locais de interação professor e aluno. Nesta vertente, compreende-se que os trabalhos conectados aos afazeres culturais e sociais dos alunos, resultantes no conhecimento escolar, são condicionados por fatores de ordens diversas, socioculturais e político-econômicas, por exemplo. Este conhecimento, para fins de ensino e aprendizagem, é organizado por mecanismos de pedagogização, constituindo um saber escolar elaborado na relação com o outro.

Portanto, na concepção crítica, o currículo integrado, apresentado às escolas pela reestruturação curricular no início do ano de 2011 e posto em prática a partir do ano de 2012, vem possibilitando o entendimento do contexto, da realidade, das culturas e tradições, visando a uma participação social-democrática, responsável, ativa e solidária.

\section{CONSIDERAÇÓES FINAIS}

A reorganização do currículo no Ensino Médio gaúcho, influenciada pelas orientações de colaboratividade, dialogicidade e formatividade dos tempos atuais, tem fortes implicações no controle individualizado do trabalho docente, buscando a minimização do ensino fragmentado e sem nexo, evoluindo-se para um ensino pautado na interdisciplinaridade, nas inter-relações dos sujeitos e, dentre 
outros, na íntegra participação da comunidade escolar nos processos de ensino e aprendizagem.

No decorrer do trabalho pode-se averiguar que a grande maioria dos professores pesquisados defende o currículo reorganizado, (re)contextualizando-o em função de suas culturas e práticas locais, considerando-o como flexível e de fácil compreensão aos materiais de apoio. Do mesmo modo, qualificam os trabalhos desenvolvidos nesta vertente, dando ênfase a professores, coordenação, direção e comunidade escolar que apoiam e enriquecem os trabalhos desenvolvidos.

Neste viés, Santomé (1998, p. 45) enfatiza que "a cultura, mentalidade e expectativas de qualquer pessoa são fruto de uma história vivida no seio de uma ou várias famílias, resultado de sua participação ativa dentro de grupos sociais étnicos, de gênero, de condicionantes geográficos, históricos, biológicos, etc". Portanto, apostar na interdisciplinaridade como mecanismo de construção de saberes e qualificação dos processos de ensino e aprendizagem, além de acreditar na possibilidade de integração das diferentes áreas do saber, agregando-as às diversidades culturais, "significa defender um novo tipo de pessoa, mais aberta, flexível, solidária, democrática e crítica" (SANTOMÉ, 1998, p. 45).

Destarte, pode-se interpretar, por meio das escrituras, que os professores compreendem o currículo como mecanismo de aproximação entre os segmentos da escola, uma vez que, com a reestruturação, houve a necessidade de redefinir as práticas pedagógicas e o desenvolvimento dos processos de ensino e aprendizagem, valorizando o contexto do estudante, a opinião do colega e a emersão de atividades interdisciplinares, isto é, uma forma de abarcar os conhecimentos necessários a todos, independentemente de aspectos sociais ou culturais.

Todavia, há a necessidade de os professores continuarem à busca por uma formação continuada, capaz de proporcionar um conjunto de saberes básicos como forma de viabilizar o diálogo entre os mesmos, a escolas e os estudantes, pois cada vez mais cresce a necessidade de desenvolver trabalhos contextualizados a realidade local. Nesta perspectiva, as Diretrizes para a Formação de Professores da Educação Básica, definidas pela Resolução CNE/CP N ${ }^{\circ}$ 01/02, refletem a ideia de que essa formação deve considerar, acima de tudo, o conjunto das competências necessárias à atuação profissional, sendo fundamental, como expressa o documento, que se busque adotá-las como norteadoras, tanto da proposta pedagógica, em especial do currículo e da avaliação, quanto da organização institucional e da gestão da escola de formação.

Por fim, espera-se que este trabalho de investigação sobre a reestruturação curricular no Estado do Rio Grande do Sul possa contribuir para resgatar as questões de inter-relacionamento, interdisciplinaridade e contextualização nas práticas docentes, valorizando a proliferação de informações, a complexidade dos conteúdos, a relação entre o saber e o dizer e, dentre outros mecanismos, a eficiência da relação entre teoria e prática para qualificar o ensino básico brasileiro e diminuir os índices de evasão e reprovação. 


\section{REFERÊNCIAS}

ALBUQUERQUE, J. A; KUNZLE, M. R. O currículo e suas dimensões, multirracial e multicultural. In: Caderno Pedagógico nº 4, APP-SINDICATO 60 ANOS. 2006.

BRASIL. Secretaria da Educação Média e Tecnológica. Parâmetros Curriculares para o Ensino Médio. Brasília: MEC, 1999.

BRASIL. Secretaria da Educação Média e Tecnológica. PCN+: Ensino Médio -orientações educacionais complementares aos Parâmetros Curriculares Nacionais. Brasília: MEC, 2002.

BRASIL. Lei $\mathbf{n}^{\circ}$ 9.394, de 20 de dezembro de 1996. Diretrizes e Bases da Educação Nacional. Brasília, DF, 1996. P. 1-31. Disponível em: http://portal.mec.gov.br/seed/ arquivos/pdf/tvescola/leis/lein9394.pdf. Acesso em 25 de abril de 2011.

FAZENDA, I. C. A. O que é Interdisciplinaridade? São Paulo: Cortez, 2008.

FORQUIN, Jean-Claude. Escola e cultura: as bases sociais e Epistemológicas do conhecimento escolar. Porto Alegre: Artes Médicas, 1993.

FREITAS, M. T. A. Abordagem sócio-histórica como orientadora da pesquisa qualitativa. Cadernos de pesquisa. no. 116, p. 21-39. SP, Julho, 2002.

GRAMSCI, A. Cadernos do cárcere. Vol.1. Rio de Janeiro: Civilização Brasileira, 1999.

LOPES, A. C. Pensamento e política curricular - entrevista com William Pinar. In:

Políticas de currículo em múltiplos contextos. São Paulo: Cortez, 2006.

LIBÂNEO, J. C. Didática. São Paulo: Cortez, 1994.

MATOS, K. LOPES, S. VIEIRA, S. Pesquisa Educacional: o prazer de conhecer. Fortaleza: Edições Demócrito Rocha, UECE, 2001.

MINAYO, M. C. S. O desafio do conhecimento: pesquisa qualitativa em saúde. $6^{\mathrm{a}}$ ed. São Paulo: Hucitec-Abrasco; 1999.

MINAYO, M. C. S. (Org.). Pesquisa social: teoria, método e criatividade. Rio de Janeiro: Vozes, 2001.

MINAYO, M. C. de S. (Org.). Pesquisa social: teoria, método e criatividade. 22. ed. Rio de Janeiro: Vozes, 2003.

PINHEIRO, P. P. Direito Digital. 4ª ed. São Paulo: Editora Saraiva, 2010

RICARDO, E. Competências, interdisciplinaridade e contextualização: dos Parâmetros Curriculares Nacionais a uma compreensão para o ensino das Ciências. Tese (Doutorado em Educação Científica e Tecnológica). Universidade Federal de Santa Catarina, Florianópolis: UFSC, 2005.

SACRISTÁN J. G; PÉREZ GÓMEZ, A. I. Compreender e transformar o ensino. Porto Alegre: ArtMed, 2000. 
SACRISTÁN, J. G. Aproximação ao conceito de currículo. In: SACRISTAN, J. G. O currículo: uma reflexão sobre a prática. Porto Alegre: ArtMed, 1999. Cap. 1, p. 13-87.

SACRISTAN, J. G. A cultura para os sujeitos ou os sujeitos para a cultura? O mapa mutante dos conteúdos na escolaridade. In: SACRISTAN, J. G. Poderes instáveis em educação. Porto Alegre: ArtMed, 1999. Cap. 4, p. 147-206.

SANTOMÉ, J. T. Globalização e interdisciplinaridade: o currículo integrado. Porto Alegre: Artes Médicas, 1998.

SAVIANI, D. Sobre a Concepção de Politecnia. Rio de Janeiro: Fundação Oswaldo Cruz, 1989.

SILVA, T. T. Documentos de Identidade: uma introdução às teorias do currículo. Belo Horizonte: Autêntica, 2005.

SMED. Cadernos Pedagógicos no 9. Porto Alegre, 1999

UNESCO. Protótipos Curriculares de Ensino Médio e Ensino Médio Integrado: Resumo Executivo. Brasília, Debates ED, n.1, maio 2011. 